\title{
Variable phenotypic presentation of iron overload in H63D homozygotes: are genetic modifiers the cause?
}

P Aguilar-Martinez, M Bismuth, M C Picot, C Thelcide, G-P Pageaux, F Blanc, P Blanc, J-F Schved, D Larrey

Laboratory of

Haematology, CHU of

Montpellier, 34295

Montpellier, France

P Aguilar-Martinez $\dagger$

C Thelcide

J-F Schved

Department of

Hepatogastroenterology, CHU of Montpellier, 34295 Montpellier,

France

M Bismuth $\dagger$

G-P Pageaux

P Blanc

D Larrey

Department of

Epidemiology, CHU of

Montpellier, 34295

Montpellier, France

M C Picot

Department of

Internal Medicine,

CHU of Montpellier,

34295 Montpellier,

France

F Blanc

† These two authors

contributed equally to this

work.

Correspondence to:

Dr P Aguilar-Martinez,

Laboratoire d'Hématologie,

CHU Saint Eloi, 34295

Montpellier CEDEX 5,

France.

p-martinez@

chu-montpellier.fr

Accepted for publication

19 December 2000

\begin{abstract}
Background-First considered as a polymorphism of the HFE gene, the H63D mutation is now widely recognised as a haemochromatosis associated allele. But few H63D homozygotes with clinical manifestations of hereditary haemochromatosis (HH) have been reported. Concurrently, an increasing number of genes have been shown to interact with $H F E$ in iron metabolism.
\end{abstract}

Aims-To describe the clinical expression of iron overload (IO) associated with H63D homozygosity, and search for potential genetic modifiers (within the $H F E$ or other genes) that could explain the variability of the phenotypes.

Patients and methods-We retrospectively analysed the clinical phenotype of 56 H63D homozygotes referred for a personal or family history of IO. For each subject we examined intragenic $H F E$ haplotypes and transferrin receptor (TfR) gene polymorphisms and searched for the Y250X mutation on the TFR2 gene. Additionally, we sequenced the $H F E$ gene of H63D homozygotes with $\mathrm{HH}$.

Results-Fifty of 56 subjects had biological and/or clinical abnormalities of iron metabolism. Up to two thirds of patients $(n=34)$ had no acquired cause of IO. Among these, 12 had a phenotypic diagnosis of HH. In the iron loaded group there was a strong prevalence of male patients. No correlation was found between the potential genetic modifiers and phenotypes. No additional mutation of $H F E$ was identified.

Conclusion-The variable phenotypes associated with H63D homozygosity do not appear to be linked to other $H F E$ mutations, to the TFR2 Y250X mutation, or to $H F E$ or TfR gene intragenic polymorphisms. The exact role of H63D homozygosity in $\mathrm{IO}$ and $\mathrm{HH}$ needs to be further investigated in unselected populations. (Gut 2001;48:836-842)

Keywords: haemochromatosis; H63D homozygotes; phenotypic variability; HFE haplotypes; transferrin receptor gene

The most common genotype associated with clinical manifestations of hereditary haemochromatosis $(\mathrm{HH})$ corresponds to the ancestral C282Y mutation at the homozygous state on the HFE gene identified by Feder et al in $1996 .{ }^{1}$ The recently published EASL consensus conference on haemochromatosis offers more up to date knowledge of the disease. ${ }^{2}$ While C282Y homozygosity accounts for more than $80 \%$ of $\mathrm{HH}$ in most countries worldwide with a predominantly Northern European population, ${ }^{134}$ other HFE genotypes are associated with a typical presentation of $\mathrm{HH}$ among which are the compound heterozygous state for C282Y and the H63D mutation, ${ }^{145}$ and a few private mutations. ${ }^{67}$ The significance of the H63D mutation on the $H F E$ gene was at first controversial. Feder et al suggested it could be either a causative mutation or a polymorphism $^{1}$; a few authors then considered it as a simple polymorphism. ${ }^{8}$ The implication of the H63D mutation as a deleterious event on the $H F E$ gene was subsequently established by clinical and molecular studies. Firstly, an excess of H63D alleles was clearly demonstrated among $\mathrm{HH}$ patients. ${ }^{19} 10$ Then, compound heterozygotes for the $\mathrm{C} 282 \mathrm{Y}$ and $\mathrm{H} 63 \mathrm{D}$ mutations were found to express $\mathrm{HH}$, even though with less penetrance than C282Y homozygotes..$^{13-11}$ In 1998, in vitro evidence for the functional consequences of the H63D mutation in $H F E$ protein activity was reported. $^{12}$

The causative role of the H63D mutation in $\mathrm{HH}$ or iron overload (IO) is now established but the question of the penetrance of this allele is still unclear. Variability in phenotypic expression is observed in many monogenic diseases, and $H F E$ related $\mathrm{HH}$ is no exception. Asymptomatic C282Y homozygotes have been reported $^{13}$ and the penetrance of the compound heterozygous state for C282Y and H63D seems to be incomplete. ${ }^{3-5}$ Moreover, clinical expression of IO in H63D homozygotes is still a matter of debate and represents a recurring question for physicians who see $\mathrm{HH}$ patients. However, to our knowledge, comprehensive data on a large cohort of such homozygotes have not been reported. To further investigate the relationship between H63D homozygosity and IO, we studied the clinical and genetic characteristics of 56 probands with this genotype.

Abbreviations used in this paper: $\mathrm{HH}$, hereditary haemochromatosis; IO, iron overload; Tf, transferrin; TfR, transferrin receptor; TFR2, transferrin receptor 2; HII, hepatic iron index; OR, odds ratio; DIOS, dysmetabolic iron overload syndrome; PCT, porphyria cutanea tarda. 
As variable clinical penetrance of a given allele can be due to genetic modifiers, we tested a number of genetic factors which could be involved in the variable phenotypic expression associated with H63D homozygosity. Genetic modifiers that may explain such a variability can be intragenic polymorphic sequences, extrinsic genetic factors such as other genes implicated in the same metabolic pathway, or environmental factors. Here we have analysed intragenic haplotypes and searched for new mutations in the HFE gene. In addition, we tested the hypothesis that transferrin receptor $(T f R)$ varieties could influence $H F E$ protein behaviour by studying intragenic polymorphisms of the TfR gene. ${ }^{14}$ Finally, we searched for the Y250X mutation on the transferrin receptor 2 (TFR2) gene which was recently implicated in non-HFE linked haemochromatosis. $^{15}$

\section{Patients and methods}

PATIENTS

The study was carried out on 968 consecutive samples received in our laboratory for $H F E$ genotyping. Reasons for the search for $H F E$ mutations were: (1) biological and/or clinical suspicion of $\mathrm{HH}$; (2) family screening for $\mathrm{HH}$; or (3) known diagnosis of $\mathrm{HH}$. C282Y and H63D mutations were systematically screened in all subjects. Blood samples were obtained after informed written consent. Overall, 60 individuals were $\mathrm{H} 63 \mathrm{D}$ homozygotes.

Clinical, biological, and histological parameters were evaluated for each subject as well as treatments. A questionnaire was established and completed using the medical records of the patients. The parameters studied were: age at the moment of DNA analysis; sex; indication for the search for $H F E$ mutations; and personal and family history (including $\mathrm{HH}, \mathrm{IO}$, diabetes, hepatic disease, and cancer). Clinical criteria for $\mathrm{HH}$ were collected, among which were fatigue, diabetes, endocrinopathy, cardiopathy, hepatopathy, arthropathy, and skin lesions. Additionally, we calculated body mass index and looked for the presence of high blood pressure. The following biological parameters were assessed: serum iron, transferrin saturation, serum ferritin, glycaemia, cholesterol, and triglycerides. Blood cell count and viral hepatitis status were examined in all patients. When a liver biopsy had been performed, we recorded the presence of fibrosis, cirrhosis, hepatic iron concentration, and hepatic iron index (HII). Finally, when a depletive treatment had been performed, we noted the number, volume, and periodicity of venesections to calculate total body iron removed. The criteria for $\mathrm{HH}$ have been reviewed in light of the recently published EASL consensus conference on haemochromatosis. $^{2}$

METHODS

Diagnosis of C282Y and H63D mutations

Both $H F E$ mutations were investigated using a method previously described, based on modification of natural restriction sites. ${ }^{16}$
Table 1 HFE genotypes of the whole population referred for a personal or family history of iron overload (patients) compared with a control group (controls) from our area (1276 unselected newborns) ${ }^{18}$

\begin{tabular}{lrrrrr}
\hline & \multicolumn{2}{c}{ Patients } & & \multicolumn{2}{c}{ Controls } \\
\cline { 2 - 3 } \cline { 5 - 6 } HFE genotype & $n$ & $\%$ & & \multicolumn{2}{c}{$\%$} \\
\hline $\mathrm{m} 1 \mathrm{~m} 1$ & 178 & 18.4 & & 2 & 0.2 \\
$\mathrm{~m} 1 \mathrm{~N}$ & 141 & 14.6 & & 58 & 4.6 \\
$\mathrm{~m} 1 \mathrm{~m} 2$ & 85 & 8.8 & & 15 & 1.2 \\
$\mathbf{m} 2 \mathbf{m} 2$ & $\mathbf{6 0}$ & $\mathbf{6 . 2}$ & & $\mathbf{3 6}$ & $\mathbf{2 . 8}$ \\
$\mathrm{m} 2 \mathrm{~N}$ & 170 & 17.6 & & 345 & 27.0 \\
NN & 334 & 34.5 & & 820 & 64.3 \\
Total & 968 & 100 & & 1276 & 100 \\
\hline
\end{tabular}

$\mathrm{m} 1=\mathrm{C} 282 \mathrm{Y} ; \mathrm{m} 2=\mathrm{H} 63 \mathrm{D}$.

Haplotype analysis of the HFE gene

Two intragenic polymorphisms of the $H F E$ gene, IVS2 (+4) t/c and IVS5 (+907) g/a, were studied in each subject, as described previously. ${ }^{17}$

Sequence analysis of the HFE gene

Exons 1-6 and exon-intron boundaries of the $H F E$ gene were sequenced using a "big dye terminator" kit on an ABIprism 310 apparatus (Applied Biosystems, Foster City, USA) according to the manufacturer's recommendations. Primer sequences and polymerase chain reaction conditions have been described elsewhere. ${ }^{17}$

Genetic polymorphism of the TfR gene

The TfR gene polymorphism Ser142Gly was analysed using a modification of a BanI restriction site, as described previously. ${ }^{14}$

Characterisation of the TFR2 Y250X mutation The newly described Y250X mutation on the TFR2 gene was searched for in all H63D homozygotes using modification of a MaeI restriction site, as described previously. ${ }^{15}$

\section{Statistical analysis}

Statistical analysis was performed using the $\chi^{2}$ or Fisher's exact test for qualitative variables. Odds ratios (OR) and 95\% confidence intervals (CI) were calculated. The Mann-Whitney test was used for quantitative parameters. The statistical software SAS (SAS Institute, Inc., North Carolina, USA) version 6.11/UNIX (proc freq, proc univariate proc nparlway) was used for statistical analysis.

\section{Results}

\section{CLINICAL DATA}

HFE genotypes of the 968 tested subjects are given in table 1. The frequency of H63D homozygotes among patients was significantly higher than in a control sample of 1276 unselected newborns in our area $\left(\mathrm{p}=10^{-4}\right.$, OR 2.3 (95\% CI 1.5-3.5)). ${ }^{18}$

Of the 60 identified H63D homozygotes, full data were obtained for 56 who were then included in the study. There were 42 males $(75 \%)$ and 14 females (25\%). Mean age was 53.8 (14) years. Reasons for the search for $H F E$ mutations in these H63D homozygotes are listed in table 2. 
Table 2 H63D homozygotes: reasons for diagnosis

\begin{tabular}{lr}
\hline Reason & No subjects \\
\hline Clinical and/or biological suspicion of hereditary haemochromatosis & 38 \\
Family screening (hereditary haemochromatosis or iron overload) & 6 \\
Known hereditary haemochromatosis & 12 \\
Total & 56 \\
\hline
\end{tabular}

Only six H63D homozygotes in this cohort had no biological signs of IO. Mean age of this group was lower (42.3 (21.5) years) than that of iron loaded subjects (54.7 (12) years) but the difference was not statistically significant $(p=0.06)$. The number of men and women was the same in both groups. All six were diagnosed through family screening.

Fifty of 56 H63D homozygotes (89.3\%) had biological and/or clinical abnormalities of iron metabolism (fig 1): 39 men and 11 women (sex ratio males to females 3.5). An acquired cause of IO was searched among the iron loaded H63D homozygotes. Nine were habitual drinkers (that is, consuming more than $30 \mathrm{~g}$ alcohol/ day) and one had chronic viral hepatitis $B$. Three of these $50 \mathrm{H} 63 \mathrm{D}$ homozygotes $(6 \%$; two males and one female aged 38,54 , and 70 years, respectively) fulfilled the diagnosis criteria for dysmetabolic iron overload syndrome (DIOS). ${ }^{19}$ As described, transferrin saturation was normal and serum ferritin levels were elevated $(557 \mu \mathrm{g} / 1$ on average). Both males had a body mass index greater than 25 and both had hyperlipaemia. The woman had a normal body mass index and no dyslipidaemia but she had high blood pressure. In all three cases liver biopsy showed a HII lower than 1.9.

A diagnosis of porphyria cutanea tarda (PCT) was established in four of 50 iron loaded H63D homozygotes (8\%) based on clinical and biological criteria. This group comprised one family and three sporadic cases. All subjects with PCT were males and were

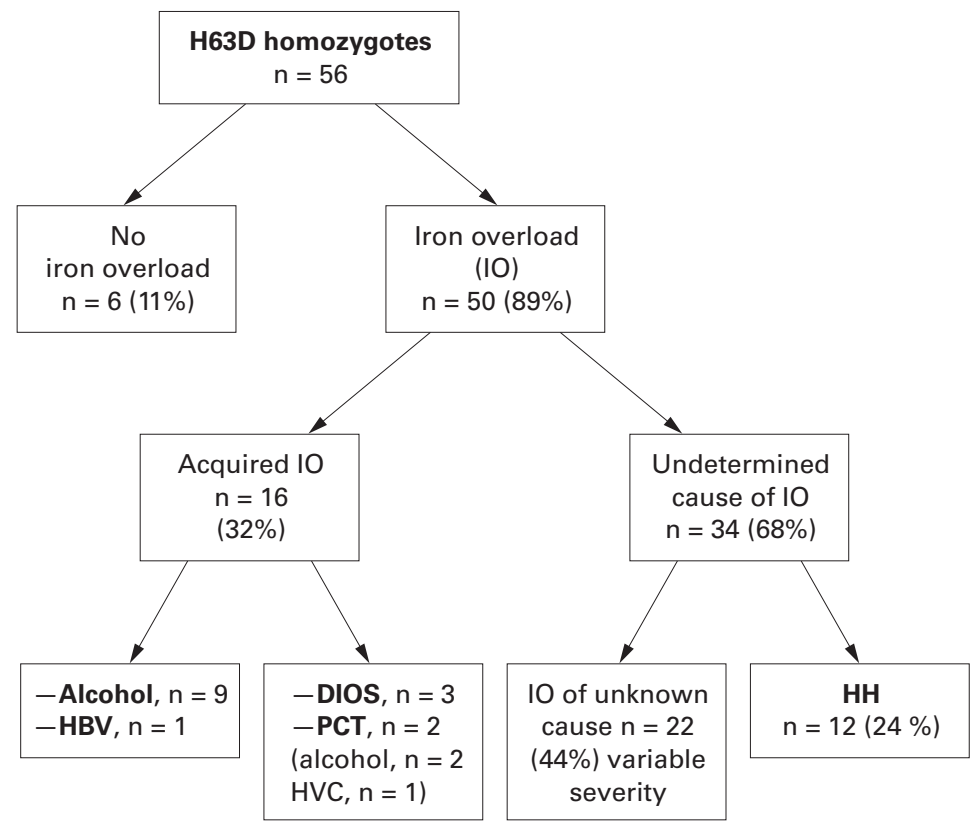

Figure 1 Classification of H63D homozygotes in this study according to the category of iron overload. HH, hereditary haemochromatosis; HBV, hepatitis $B$ virus; DIOS, dysmetabolic iron overload syndrome; PCT, porphyria cutanea tarda. undergoing phlebotomies. Two had excessive alcohol consumption while one had hepatitis C virus related hepatitis. No cause of IO was found in the fourth subject. Liver biopsy performed in two cases showed chronic hepatitis in the hepatitis $\mathrm{C}$ virus patient and a HII $<1.9$ in the second.

Thus among $50 \mathrm{H} 63 \mathrm{D}$ iron loaded subjects, $16(32 \%)$ had a secondary cause of IO. Conversely, for 34 of 50 (68\%) H63D homozygotes, abnormalities of iron metabolism were not associated with a known aetiology. One was the fourth patient with PCT. Twelve of these patients had a phenotypic diagnosis of $\mathrm{HH}$ (table 3). The sex ratio (male/ female) was 5 and mean age at diagnosis was 53.4 (14) years (range 35-77). Eleven of these 12 individuals had a liver biopsy. HII was greater than 2 in eight subjects; it was less than 1.9 in one subject and was not determined in two. Fibrosis was present in six of 11 liver biopsies; three of these six also showed cirrhosis. A histologically proved hepatocarcinoma with cirrhosis was identified in two patients who died shortly after diagnosis. Mean mobilised body iron was 7.3 (7.6) g (range 1.8-27), calculated for all patients except those with hepatocarcinoma. Finally, four of $12 \mathrm{HH}$ subjects had a family history of $\mathrm{HH}$ and two had a family history of hepatocarcinoma.

Among the 22 remaining individuals, abnormalities of iron metabolism had a variable expression and were not associated with a well defined pathology. A family history of $\mathrm{HH}$ or IO was found in five of 22 cases (23\%). The sex ratio of this group of 22 subjects was 1.6 and mean age was 54.1 (11.6) (range 35-77). Fatigue and arthritis were the two most frequent clinical symptoms (40\%). Mean serum ferritin level was $824 \mu \mathrm{g} / 1$ (range 26-1715) and mean transferrin saturation was $57.8 \%$ (range 29-96). Five had a liver biopsy (HII was $<1.9$ in two and not determined in three). One individual who had a liver biopsy was diagnosed with a hepatocarcinoma but hepatic iron was not assessed. Four subjects had been occasionally phlebotomised $(<5 \mathrm{~g}$ iron removed). Comparisons of mean age, mean serum ferritinaemia, and mean transferrin saturation between males and females showed no significant differences. Accordingly, in these 22 subjects abnormalities of iron metabolism could not be related to any known aetiology, the only common feature being H63D homozygosity associated with hereditary IO in $25 \%$.

HAPLOTYPE ANALYSIS OF THE HFE GENE A single intragenic HFE haplotype (IVS2 (+4) c/c, IVS4 (+907) a/a) was observed among the 56 H63D homozygotes, as described previously. ${ }^{20}$ Some of the patients' haplotypes included in the present study have been reported in part elsewhere. ${ }^{17}$

SEQUENCE ANALYSIS OF THE HFE GENE All H63D homozygous patients with a phenotypic diagnosis of $\mathrm{HH}$ were submitted to DNA sequencing of the $H F E$ gene. No sequence 
Table 3 Clinical and biological data on 12 H63D homozygotes with a phenotype of hereditary haemochromatosis (HH)

\begin{tabular}{|c|c|c|c|c|c|c|c|c|c|c|c|}
\hline \multirow[b]{2}{*}{ Patient No } & \multirow[b]{2}{*}{ Sex } & \multirow[b]{2}{*}{$\operatorname{Age}^{*}(y)$} & \multirow[b]{2}{*}{ Family history } & \multirow[b]{2}{*}{$\begin{array}{l}\text { Transferrin } \\
\text { saturation (\%) }\end{array}$} & \multirow{2}{*}{$\begin{array}{l}\text { Serum } \\
\text { ferritin } \\
(\mu g / l)\end{array}$} & \multirow[b]{2}{*}{$H I I$} & \multicolumn{2}{|c|}{ Liver biopsy } & \multirow[b]{2}{*}{$H C C$} & \multicolumn{2}{|c|}{ Body iron removed } \\
\hline & & & & & & & Fibrosis & Cirrhosis & & Amount (g) & $\begin{array}{l}\text { Duration } \\
\text { (months) }\end{array}$ \\
\hline 1 & $\mathrm{~F}$ & 35 & $\mathrm{HH}, \mathrm{HCC}$ & 93 & 991 & 11.03 & Yes & No & - & 6.9 & 33 \\
\hline 2 & $\mathrm{~F}$ & 48 & No & 75 & 4816 & 6.4 & Yes & Yes & - & 11.4 & 63 \\
\hline 3 & $\mathrm{M}$ & 39 & No & 68 & 1000 & nd & nd & nd & - & 10 & 66 \\
\hline 4 & M & 40 & No & 72 & 1498 & 2.4 & No & No & - & 1.8 & 16 \\
\hline 5 & M & 43 & $\mathrm{HH}$ & 47 & 987 & 1.47 & No & No & - & 27 & 198 \\
\hline 6 & M & 47 & No & 50 & 886 & nd & No & No & - & 12.6 & 102 \\
\hline 7 & M & 54 & $\mathrm{HH}$ & 51 & 1270 & 2.69 & Yes & No & - & 3 & 24 \\
\hline 8 & M & 55 & $\mathrm{HH}$ & 47 & 645 & 2.24 & No & No & - & 2.7 & 16 \\
\hline 9 & M & 63 & No & 63 & 1320 & nd & Yes & No & - & 9 & 49 \\
\hline 10 & M & 65 & $\mathrm{HC}$ & 61.5 & 1410 & 4.06 & Yes & Yes & Yes & 0 & 0 \\
\hline 11 & $\mathrm{M}$ & 75 & No & 95 & 2220 & 2.57 & No & No & - & 2.4 & 10 \\
\hline 12 & M & 77 & No & 49 & 1220 & 2.12 & Yes & Yes & Yes & 0.2 & 0.5 \\
\hline Mean & & 53.4 & & 64.2 & 1522 & & & & & 7.3 & \\
\hline (SD) & & (14) & & (17) & $(1100)$ & & & & & $(7.6)$ & \\
\hline
\end{tabular}

$\mathrm{HH}$, hereditary haemochromatosis; HCC, hepatocarcinoma; HII, hepatic iron index; nd, not determined.

Normal range: transferrin saturation 23-43\%; serum ferritin: men 40-300 $\mu \mathrm{g} / 1$, women $30-185 \mu \mathrm{g} / 1$.

changes were found apart from the above reported polymorphisms.

GENETIC POLYMORPHISM OF THE TfR GENE

The TfR Ser142Gly polymorphism was examined for all 56 H63D homozygotes. No correlation was found between any of the TfR alleles or in the corresponding TfR genotypes, and the clinical phenotypes of the 56 subjects. In particular, the Ser142 allele which has been found to be associated with carcinogenesis in association with the C282Y mutation ${ }^{2122}$ was not found to be linked with severe manifestations in H63D homozygotes. Moreover, the four H63D homozygous patients with hepatocarcinoma had no specific TfR allele or genotype.

CHARACTERISATION OF THE TFR2 Y250X MUTATION

All $56 \mathrm{H} 63 \mathrm{D}$ homozygotes were investigated for the presence of the Y250X mutation on the TFR2 gene. None was found. Some of these results concerning the $12 \mathrm{H} 63 \mathrm{D}$ homozygotes with a phenotype of $\mathrm{HH}$ have been reported elsewhere as part of a larger series of non-C282Y HH patients (Aguilar-Martinez, personal communication).

\section{Discussion}

CLINICAL VARIETY OF IO ASSOCIATED WITH H63D HOMOZYGOSITY

The allelic frequency of the H63D mutation is very variable worldwide. ${ }^{23}$ In the general population in our area it is $17 \%$, and the frequency of H63D homozygotes reaches 3\%. ${ }^{17}{ }^{18}$ This high prevalence can be explained by our geographical position in southern France. The population of this area is heterogeneous, comprising people originating from various Mediterranean countries, including Spain, where the H63D mutation has the highest frequency in the world. ${ }^{24} 25$ However, the frequency of the H63D homozygous genotype was significantly higher $(\mathrm{p}<0.0001)$ among patients referred for a personal or family history of IO than in the general population of the area. One explanation could be that if H63D homozygosity leads to different degrees of IO due to a variable penetrance of this genotype, a higher number of
H63D homozygotes in the general population would allow more iron loaded H63D homozygotes to be found than in studies on Northern European populations. Indeed, in previously described populations from the USA, Canada, and Australia ${ }^{26-29}$ the H63D mutation was less frequent, resulting in less iron loaded H63D homozygotes being diagnosed. Here, we investigated a group of $56 \mathrm{H} 63 \mathrm{D}$ homozygotes. Their clinical presentation varied considerably; only six were recruited through family screening not exhibiting IO.

ACQUIRED IO IS FOUND IN LESS THAN ONE THIRD OF H63D HOMOZYGOTES

All subjects investigated in this study were carefully screened for secondary causes of IO. Excessive alcohol intake and viral hepatitis were found in 13 cases (26\%). Three of these had clinical manifestations of PCT (two with excessive alcohol consumption and one with hepatitis $\mathrm{C}$ virus). The worsening role of $\mathrm{IO}$ in PCT is well known in both sporadic and family forms, and a high prevalence of $H F E$ gene mutations has been demonstrated in PCT. ${ }^{30} 31$ The prevalence of the C282Y mutation in PCT seems to be higher in subjects of Northern European descent than in individuals from southern countries. ${ }^{32} 33$ This could be because of the respective distribution of $H F E$ mutations in both populations. Thus $H F E$ genotypes that favour iron accumulation seem to contribute to the development of PCT with a gradient locating C282Y in the north of Europe and H63D in the south. ${ }^{33}$ Three additional patients fulfilled the criteria for DIOS. ${ }^{19}$ DIOS has been described as a disease distinct from HH. However, the prevalence of $H F E$ gene mutations in this syndrome is high $(60 \%),{ }^{34}$ and some authors suggested that DIOS could be a clinical form of $\mathrm{HH} .{ }^{35}$ Recently, other groups have argued for a unique origin of DIOS and HFE related $\mathrm{HH} .{ }^{36}{ }^{37}$

NEARLY 70\% OF H63D HOMOZYGOTES HAD NO DETECTABLE CAUSE OF IO

In these 34 subjects, IO can be severe or mild. Severe IO was observed in nearly $25 \%$ of the 50 iron loaded subjects; 12 patients presented a phenotypic diagnosis of $\mathrm{HH}$. In our centre, we 
have previously shown that severe IO is mostly due to homozygosity for the C282Y mutation $(81.8 \%) .^{5}$ In this preliminary series of 99 patients, compound heterozygotes accounted for $7.1 \%$ of $\mathrm{HH}$ cases while H63D homozygotes represented $4 \%$ of the total. The non- $H F E$ linked $\mathrm{HH}$ phenotype was present in only $3 \%$ of this series. The phenotypic expression of $\mathrm{HH}$ in the $12 \mathrm{H} 63 \mathrm{D}$ homozygotes was not different from C282Y homozygotes except for the sex ratio. The sex ratio (male/female) was 5 in H63D homozygotes manifesting $\mathrm{HH}$ whereas it was only 1.5 in our sample of C282Y homozygotes (data not shown). A high prevalence of males among subjects with so-called "mild HFE genotypes" (H63D, S65C) with clinical manifestations has been observed previously. ${ }^{6}$ Other parameters such as age of occurrence of the disease, clinical, biological and histological manifestations, as well as removed iron were not different in H63D homozygotes with $\mathrm{HH}$ and those usually reported in $\mathrm{HH}$ patients. It is noteworthy that two of $12(16.6 \%)$ homozygous H63D HH patients had hepatocarcinoma. Such a high prevalence of hepatocarcinoma is not observed in classical haemochromatosis ${ }^{38}$ and a normal prevalence of the $\mathrm{C} 282 \mathrm{Y}$ mutation has been reported in patients with hepatocarcinoma. ${ }^{39}$ In this last work the H63D mutation was not investigated. Because of the small number of affected subjects in our series, further studies are needed to evaluate the relationship between H63D and hepatocarcinoma.

Iron overload of milder severity (minimal or modest according to the definition of the EASL consensus conference ${ }^{2}$ ) was present in the remaining 22 individuals. Compared with the group of $\mathrm{H} 63 \mathrm{D}$ patients with $\mathrm{HH}$, mean age was not different (54.1 $v 53.4$ years) whereas the sex ratio was lower (1.6 $v 5$ in H63D homozygotes with $\mathrm{HH}$ ). The higher number of females in this group could explain the weaker expression of the H63D genotype, as a result of menstrual iron loss and pregnancy.

Thus H63D homozygosity can be associated with a variety of phenotypes, including severe or mild IO, or no IO. If we assume that H63D homozygosity plays a deleterious role and leads to difficulties in regulating iron homeostasis, we must take into account the fact that genetic or environmental factors can modify the phenotype. A missing factor or an additional regulatory element could modulate IO, lowering or aggravating its expression.

GENETIC MODIFIERS LOCATED ON THE HFE, TfR, AND TFR2 GENES DO NOT SEEM TO INFLUENCE THE PHENOTYPE OF H63D HOMOZYGOTES

To explain the variable phenotypes observed in H63D homozygotes, we tested potential genetic factors that could modify expression of the genotype. Intragenic polymorphisms in the gene responsible for their synthesis have been shown to modulate expression of certain proteins. This is the case, for example, for the coagulation FVII $353 \mathrm{Gln}$ allele which lowers the level of circulating FVII by $25-40 \%{ }^{40}$ In the same way, a polymorphic TA repeat in the 5 ' region of the UGT1A1 gene has been demonstrated to induce Gilbert syndrome by lowering the production of the bilirubin UDPglucuronosyltranferase 1 protein when fasting. ${ }^{41}$

However, in our panel the search for intra- or juxtagenic $H F E$ polymorphisms was unsuccessful, and the H63D mutation was linked to a unique intragenic haplotype. This finding is in agreement with other reports, ${ }^{20}$ even if the H63D mutation has been found to be associated with a different haplotype. ${ }^{42}$ Furthermore, previous studies failed to find any additional mutation associated with $\mathrm{H} 63 \mathrm{D}$ on the $H F E$ gene in homozygous subjects with a $\mathrm{HH}$ phenotype. ${ }^{12043}$ This was also the case for the $12 \mathrm{HH}$ H63D homozygotes in our study. Thus genetic factors linked to the $H F E$ gene do not seem to be the determinants of phenotypic expression of $\mathrm{HH}$ in $\mathrm{H} 63 \mathrm{D}$ homozygotes. However, as we have not screened the full length genomic sequence of $H F E$, we cannot exclude the fact that a modifier, located on deep intronic sequences or in the $5^{\prime}$ or $3^{\prime}$ distant regions, could be involved.

The transferrin receptor (TfR) gene is one of the main candidate genes that could participate in modifying $H F E$ activity. The HFE protein has been demonstrated to regulate transferrin receptor binding with transferrin (Tf) in vitro. ${ }^{12}$ In normal subjects, the $H F E$ protein has been shown to bind to $T f R$ on the cell membrane and lower its affinity for Tf. $^{12}$ Both HFE mutant proteins, C282Y and H63D, display an impaired inhibiting effect on $T f R$ binding to Tf. More recent data have confirmed the inhibitory effect of $H F E$ on $T f R$ but seem to indicate that it could be related to the intracellular biosynthesis pathway of both proteins. ${ }^{44}$ Moreover, the H63D mutation is located on the HFE $\alpha 1$ domain and it is noteworthy that the $T f R$ binding site on $H F E$ has been shown to be located on the $\mathrm{C}$ terminal $\alpha 1$ domain of $H F E$ and adjacent loop. ${ }^{45}$ TfR mutations have been investigated in patients with $\mathrm{HH}$ in the absence of the C282Y mutation, either in the homozygous or compound heterozygous state. ${ }^{46}$ This study failed to find any deleterious sequence alteration on the TfR gene but identified a small number of previously described TfR polymorphisms. ${ }^{14}$ Concurrently, a relationship between specific $T f R$ polymorphisms, the $\mathrm{C} 282 \mathrm{Y}$ mutation, and carcinogenesis has been reported. ${ }^{2122}$ The authors suggested that this could reflect an enhanced IO process in relation to $H F E$ mutants. Newly described animal models strengthen the hypothesis of a role for TfR to explain non-HFE related $\mathrm{HH}$ phenotypes. ${ }^{47}$ In the present study we failed to find any correlation between the clinical severity of IO in H63D homozygotes and a specific $T f R$ allele, even in subjects with hepatocarcinoma. However, we have not tested the whole $T f R$ gene sequence implicated in the relationship with $H F E .^{45}$ More recently, a mutation (Y250X) on a homologous protein to $T f R$, TFR2, has been suggested to be involved in severe IO in humans. ${ }^{15}$ Moreover, one of the patients with this mutation was also a H63D homozygote. This association could suggest that the Y250X mutation on the TFR2 gene is 
responsible for IO in H63D homozygotes. In fact, none of the 56 H63D homozygotes of our sample had the Y250X mutation. Thus our results do not support the fact that this mutation could be the common mechanism underlying IO in $\mathrm{H} 63 \mathrm{D}$ homozygotes in our area. It seems highly probable that the Y250X mutation, which has been found in two unrelated Sicilian families, could be a private mutation in this island population. Its association with H63D homozygosity, which is more widespread, was certainly fortuitous.

\section{NON-GENETIC FACTORS COULD MODIFY THE PHENOTYPIC EXPRESSION OF H63D HOMOZYGOSITY}

The genetic modifiers investigated in the present study did not appear to be implicated in the variable phenotypic expression of H63D homozygotes. In contrast, some non-genetic factors could be involved such as age and sex. Firstly, mean age in the group of H63D homozygotes who did not express any sign of IO was lower than in the group of individuals with IO (42.5 $v 54.7$ years). Secondly, there was a high prevalence of males in the iron loaded groups, especially among those with the severe phenotypes. These age and sex influences need to be confirmed in additional H63D homozygotes.

\section{Conclusion}

In a group of 56 H63D homozygotes, recruited on the basis of the presence of personal or family disorders of iron metabolism, we found a wide variety of phenotypes, from normal individuals to patients with severe IO. The search for genetic modifiers in the $H F E, T f R$, and TFR2 genes was negative. However, other as yet unknown genetic or non-genetic modulating factors could be involved. A prospective study on non-selected H63D homozygote adults from the general population may help reach definitive conclusions. Nevertheless, when a diagnosis of H63D homozygosity is made, it seems to warrant a clinical and biological follow up, particularly in men, as some of these individuals can develop severe phenotypes, including haemochromatosis.

1 Feder JN, Gnirke A, Thomas W, et al. A novel MHC class I-like gene is mutated in patients with hereditary haemochromatosis. Nat Genet 1996;13:399-408.

2 Adams P, Brissot P, Powel LW. EASL international consensus conference on haemochromatosis. $\mathcal{F}$ Hepatol 2000;33: 485-504.

3 Ramrakhiani S, Bacon B. Haemochromatosis-advances in molecular genetics and clinical diagnosis. F Clin Gastroenterol 1998;27:41-6.

4 Beutler E. Genetic irony bejond hemochromatosis: clinical effects of HLA-H mutations. Lancet 1997;349:296-7.

5 Aguilar-Martinez P, Biron C, Blanc F, et al. Compound heterozygotes for hemochromatosis gene mutations: may they help to understand the pathophysiology of the disease? Blood Cells Mol Dis 1997;23:269-76.

6 Mura C, Raguenes O, Ferec C. HFE mutations analysis in 711 hemochromatosis probands: evidence for S65C implication in mild form of hemochromatosis. Blood 1999;93 2502-5.

7 Wallace DF, Dooley JS, Walker AP. A novel mutation of HFE explains the classical phenotype of genetic hemochromatosis in a C282Y heterozygote. Gastroenterology 1999; 116:1409-12.

8 Jazwinska EC, Cullen LM, Busfield F, et al. Haemochromatosis and HLA-H. Nat Genet 1996;14:249-51.

9 Beutler E. The significance of the $187 \mathrm{G}$ (H63D) mutation in hemochromatosis. Am f Hum Genet 1997;61:762-4.

10 Fairbanks VF, Brandhagen DJ, Thibodeau SN, et al. H63D is an haemochromatosis associated allele. Gut $1998 ; 43$ : $441-2$.
11 Mura C, Nousbaum JB, Verger P, et al. Phenotype-genotype correlation in haemochromatosis subjects. Hum Genet 1997;101:271-6.

12 Feder JN, Penny DM, Irrinki A, et al. The hemochromatosis gene product complexes with the transferrin receptor and lowers its affinity for ligand binding. Proc Natl Acad Sci USA 1998;95:1472-7.

13 Rhodes DA, Raha-Chowdhury R, Cox TM, et al. Homozygosity for the predominant Cys282Tyr mutation and absence of disease expression in hereditary haemochromatosis. F Med Genet 1997;34:761-4.

14 Van Landeghem GF, Beckman LE, Sikstrom C, et al. New DNA polymorphisms define ethnically distinct haplotypes in the human transferrin receptor gene. Hum Hered 1998;48:245-50.

15 Camaschella C, Roetto A, Cali A, et al. The gene TFR2 is mutated in a new type of haemochromatosis mapping to 7q22. Nat Genet 2000;25:14-15.

16 Aguilar-Martinez P, Jeanjean P, Masmejean C, et al. Simple and rapid detection of the newly described mutations in the HLA H gene. Blood 1997;89:1835-6.

17 Aguilar-Martinez P, Thelcide C, Jeanjean P, et al. Haplotype analysis of the HFE gene: implications for the origins of hemochromatosis related mutations. Blood Cells Mol Dis 1999;25:166-9.

18 Aguilar-Martinez P, Picot MC, Boulot P, et al. Prevalence of HFE mutations in people from North Africa. Blood 2000;96(suppl 1, part 2): abstract 3662 .

19 Moirand R, Mortaji AM, Loréal O, et al. A new syndrome of iver iron overload with normal transferrin saturation. Lancet 1997;349:95-7.

20 Beutler E, West C, Gelbart T, et al. Genetic and clinical description of hemochromatosis probands and heterozygotes: evidence that multiple genes linked to the major histocompatibility complex are responsible for hemochromatosis. Blood Cells Mol Dis 1997;23:145a$145 \mathrm{~b}$.

21 Van Landeghem GFV, Beckman LE, Markevärn B, et al. Interaction between hemochromatosis and transferrin receptor genes in multiple myeloma. Lancet 1998;352: $1285-6$.

22 Beckman LE, Van Landeghem GF, Sikstrom C, et al. Interaction between haemochromatosis and transferrin receptor genes in different neoplastic disorders. Carcinogenesis 1999; 20:1231-3

23 Merryweather-Clarke AT, Pointon JJ, Shearman JD, et al. Global prevalence of putative haemochromatosis mutations. F Med Genet 1997;34 :275-8.

24 Baiget M, Barcelo MJ, Gimferrer E. Frequency of the HFE $\mathrm{C} 282 \mathrm{Y}$ and $\mathrm{H} 63 \mathrm{D}$ mutations in distinct ethnic groups living in Spain. F Med Genet 1998;35:701-4.

25 Sanchez M, Bruguera M, Bosch J, et al. Prevalence of the Cys282Tyr and His63Asp HFE mutations in Spanish patients with hereditary hemochromatosis and in controls. 7 Hepatol 1998;29:725-8.

26 Burt MJ, George PM, Upton JD, et al. The significance of haemochromatosis gene mutations in the general population: implications for screening. Gut 1998;43:830-6.

27 Adams PC. Population screening for hemochromatosis. Hepatol 1999;29:1324-7.

28 Olynyk JK, Cullen DJ, Aquilia S, et al. A population-based study of the clinical expression of the hemochromatosis gene. N Engl F Med 1999;341:718-24.

29 McDonnell SM, Hover A, Gloe D, et al. Population-based screening for hemochromatosis using phenotypic and DNA testing among employees of health maintenance organizations in Springfield, Missouri. Am $\mathcal{F}$ Med 1999; 107:30-7.

30 Roberts AG, Whatley SD, Morgan RR, et al. Increased frequency of the haemochromatosis Cys282Tyr mutation in sporadic porphyria cutanea tarda. Lancet 1997;349:321-3.

31 Santos M, Clevers HC, Marx JJ. Mutations of the hereditary hemochromatosis candidate gene HLA-H in porphyria cutanea tarda. N Engl f Med 1997;336:1327-8.

32 Sampietro M, Piperno A, Lupica L, et al. High prevalence of the His63Asp HFE mutation in Italian patients with porphyria cutanea tarda. Hepatology 1998;27:181-4.

33 Dereure O, Aguilar-Martinez P, Bessis D, et al. HFE mutations and transferrin receptor polymorphism analysis in porphyria cutanea tarda: a prospective study of 36 cases from Southern France. Br $\mathcal{F}$ Dermatol 2001;144:533-9. (in press).

34 Deugnier Y, Moirand R, Jouanolle AM, et al. HLA-H mutations in patients with iron overload and normal transferrin saturation. Hepatology 1997;26:199A.

35 Fargion S, Sampietro M, Fracanzani G, et al. Iron overload with normal transferrin saturation: a subset of genetic hemochromatosis? Hepatology 1997;26:200A.

36 Rovati A, Bergamaschi G, Casula S, et al. The dysmetabolic iron overload syndrome is clinically and genetically distinct from HFE-related genetic hemochromatosis. Haematologica $1999 ; 84: 182-3$.

37 Orlandi E, Arbustini E, Lazzarino M. Isolated hyperferritinemia with normal transferrin saturation and dysmetabolism, in the absence of the two known mutations in the HFE gene of hereditary hemochromatosis. Haematologica 1999;84:181-2.

38 Niederau C, Fischer R, Purschel A, et al. Long term survival in patients with hereditary hemochromatosis. Gastroenterology 1996;110:1107-19.

39 Willis G, Wimperis JZ, Lonsdale R, et al. Haemochromatosis gene mutation in hepatocellular cancer. Lancet 1997; 350:565-6. 
40 Bosma PJ, Chowdhury JR, Bakker C, et al. The genetic basis of the reduced expression of bilirubin UDPglucuronosyltransferase 1 in Gilbert's syndrome. $N$ Engl $f$ Med 1995,333:1171-5.

41 Bernardi F, Marchetti G, Pinotti M, et al. Factor VII gene polymorphisms contribute to about one third of factor VI level variation in plasma. Arterioscler Thromb Vasc Biol 1996; 16:72-6.

42 Rochette J, Pointon JJ, Fisher CA, et al. Multicentric origin of hemochromatosis gene (HFE) mutations. Am f Hum Genet 1999 64:1056-62.

43 Douabin V, Moirand R, Jouanolle A, et al. Polymorphisms in the HFE gene. Hum Hered 1999; 49:21-6.
44 Salter-Cid L, Brunmark A, Li Y, et al. Transferrin receptor is negatively modulated by the hemochromatosis protein .

45 Lebron JA, Bjorkman PJ. The transferrin receptor binding site on HFE, the class I MHC-related protein mutated in hereditary hemochromatosis. F Mol Biol 1999;289:1109-18. 46 Tsuchihashi Z, Hansen SL, Quintana L, et al. Transferrin receptor mutation analysis in hereditary hemochromatosis patients. Blood Cells Mol Dis 1998;24:317-21.

47 Levy JE, Montross LK, Andrews NC. Genes that modify the hemochromatosis phenotype in mice. 7 Clin Invest 2000; 105:1209-16.

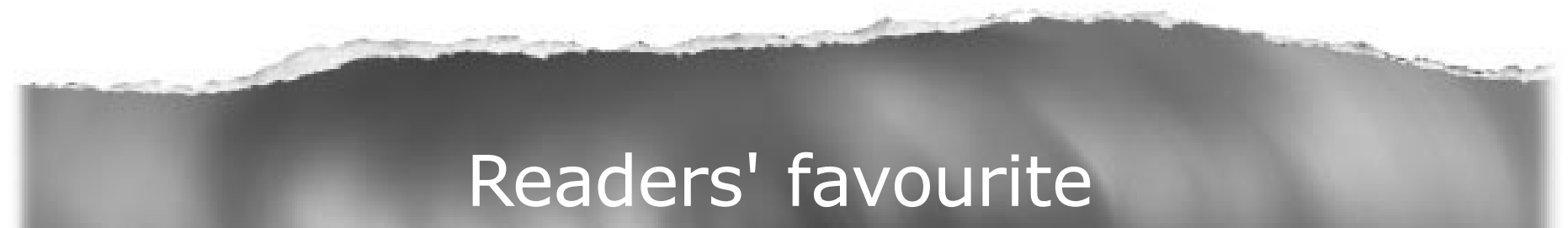

\section{Top 10}

Click on the "Top 10" button on the homepage to see which are the best read articles each month

www.gutjnl.com 